\title{
Takedown of cavopulmonary shunt at biventricular repair
}

\author{
Christopher W. Baird, MD, ${ }^{a}$ Patrick O. Myers, MD, ${ }^{\text {ab }}$ Michele Borisuk, CPNP, ${ }^{a}$ Brian Kalish, MD, \\ Sophie Hofferberth, MBBS, ${ }^{a}$ Meena Nathan, MD, ${ }^{a}$ Sitaram M. Emani, MD, ${ }^{a}$ and Pedro J. del Nido, MD $^{\mathrm{a}}$
}

Objective: With advances in valve repair and ventricular recruitment strategies, patients initially palliated with single ventricle physiology have been increasingly brought to biventricular circulation. Few data are available on the technical aspects and outcomes after takedown of the superior cavopulmonary anastomosis (bidirectional Glenn [BDG]). We reviewed a single-institutional experience in BDG takedown.

\begin{abstract}
Methods: The demographic, procedural, and outcome data were obtained for all children who had undergone BDG takedown at our institution from 2000 to 2012. The primary outcome measures were achievement of biventricular circulation, reoperation, and mortality. The secondary outcome measures were postoperative arrhythmias, superior vena cava (SVC)-right atrium (RA) or pulmonary artery stenosis at the BDG takedown site.
\end{abstract}

Results: A total of 40 patients were included during the study period, with a mean age of 4.4 years (range, 7 months to 22 years). Primary SVC-RA anastomosis was performed in 7 patients (18\%), and an anterior patch was used in 33 patients $(82 \%)$. Of the 40 patients, 38 were discharged with biventricular physiology $(98 \%)$ and mild or less ventricular dysfunction. During a mean follow-up period of $3.4 \pm 2.9$ years, 3 patients died and 1 required heart transplantation; 2 patients developed more than mild SVC stenosis requiring reintervention and 1 developed pulmonary artery stenosis. Finally, 34 patients were in normal sinus rhythm and 4 had heart block (1 pacemaker placement).

Conclusions: BDG takedown can be undertaken with a low operative risk and a low incidence of SVC or pulmonary artery stenosis or sinus node dysfunction. Additional follow-up is required to see how the reconstructed SVC grows. (J Thorac Cardiovasc Surg 2014;148:1506-11)

The direct anastomosis of the superior vena cava (SVC) to the right pulmonary artery (PA), or bidirectional Glenn (BDG) shunt, was first described in 1958. ${ }^{1}$ Longitudinal studies have since demonstrated its efficacy as a useful palliation method to augment effective pulmonary blood flow and unload the single ventricle. ${ }^{2}$ The pursuit of single ventricle palliation in a patient with 2 ventricles potentially adequate for biventricular circulation can unnecessarily subject the patient to the morbidity of single ventricle physiology. With improvement in valve repair techniques ${ }^{3-7}$ and refinement in secondary ventricular recruitment maneuvers, ${ }^{8,9}$ significant progress has been made in identifying patients amenable for biventricular repair, who were initially palliated with single ventricle physiology and subsequent cavopulmonary connections. More recently, the BDG shunt has also been used as an adjunctive strategy to assist ventricular unloading in patients with Ebstein's anomaly ${ }^{10}$

From the Department of Cardiac Surgery, ${ }^{\text {a }}$ Boston Children's Hospital and Harvard Medical School, Boston, Mass; and Division of Cardiovascular Surgery, ${ }^{\mathrm{b}}$ Geneva University Hospitals and School of Medicine, Geneva, Switzerland.

Disclosures: Authors have nothing to disclose with regard to commercial support.

Received for publication March 10, 2014; accepted for publication April 8, 2014; available ahead of print May 10, 2014.

Address for reprints: Christopher W. Baird, MD, Department of Cardiac Surgery, Boston Children's Hospital, 300 Longwood Ave, FA612, Boston, MA 02115 (E-mail: christopher.baird@childrens.harvard.edu).

$0022-5223 / \$ 36.00$

Copyright $(\odot) 2014$ by The American Association for Thoracic Surgery

http://dx.doi.org/10.1016/j.jtcvs.2014.04.018 and in patients with hypoplastic right or left ventricles undergoing attempted biventricular repair.

The surgical decisions surrounding these patients are often complex and require multiple techniques to achieve biventricular repair. However, biventricular repair often requires takedown of the cavopulmonary anastomosis by reestablishing continuity between the right atrium (RA) and SVC and reconstruction of the PA. Historically, a number of concerns have been raised regarding BDG takedown owing to potential damage to the sinoatrial (SA) node, atrial arrhythmias, resulting SVC-RA stenosis, and PA stenosis from the anterior PA dislocation. Several small series from the mid-1970s have reported the feasibility of BDG takedown. ${ }^{11-13}$ More recently, Baird and Forbess ${ }^{14}$ reported the technical considerations. However, the number of reported patients was small with minimal follow-up. Only limited conclusions have been drawn regarding the perioperative morbidity and short-term complications associated with BDG takedown. The aim of the present study was to review the techniques and outcomes of patients undergoing biventricular repair with BDG takedown from a single center's experience during an 11-year period.

\section{METHODS \\ Study Design}

The present study was a retrospective medical record review of all patients who had undergone takedown of BDG from January 2000 to January 2012 at Boston Children's Hospital. The cardiac surgery and cardiology databases were queried for all takedown of BDG procedures during the study 


$$
\begin{aligned}
& \text { Abbreviations and Acronyms } \\
& \begin{array}{l}
\text { BDG }=\text { bidirectional Glenn } \\
\text { CAVC }=\text { common atrioventricular canal } \\
\text { PA }=\text { pulmonary artery } \\
\text { RA }=\text { right atrium } \\
\text { SA }=\text { sinoatrial } \\
\text { SN }=\text { sinus node } \\
\text { SVC }=\text { superior vena cava }
\end{array}
\end{aligned}
$$

period, and all operative notes, echocardiograms, and most recent followup records were reviewed. The institutional review board approved the present study, and individual patient consent was waived. The primary outcome measures were achievement of biventricular physiology, perioperative arrhythmias, greater than mild SVC-RA anastomotic stenosis, PA stenosis at the BDG takedown site, reoperation, and mortality. The clinical and treatment variables were recorded in an attempt to determine the predictors of the endpoints.

\section{Surgical Technique}

Cardiopulmonary bypass was generally performed with moderate systemic hypothermia. Myocardial protection consisted of antegrade cold blood cardioplegia. The intracardiac portion of the repair varied, depending on the associated anatomy. The technique for cavopulmonary takedown with SVC-RA reconstruction has been previously reported. ${ }^{14}$ In brief, takedown of the cavopulmonary connection and pulmonary arterioplasty was generally performed before aortic crossclamping. The PA was either closed primarily or patched, depending on its size. Once the intracardiac portion of the repair was completed, the SVC-RA reconstruction was completed. To avoid SA nodal disruption, the RA appendage was extensively mobilized, particularly in the atrioventricular groove, and a flap of RA free wall was rotated cephalad toward the SVC to use as much native tissue as possible in re-creating the cavoatrial connection. Generally, this anastomosis was completed with 5-0 or 6-0 polypropylene suture in a running, interlocking fashion, starting at the back wall with a primary SVC-RA approximation and either primary closure of the anterior aspect, if feasible, or anterior augmentation with a patch of pericardium, pulmonary homograft (GoreTex; W. L. Gore \& Associates, Inc, Elkton, Md; or CorMatrix; CorMatrix Cardiovascular, Inc, Alpharetta, Ga)

\section{Statistical Analysis}

Statistical analyses were performed using the Statistical Package for Social Sciences software, version 21 (SPSS, Inc, Chicago, Ill). Data are presented as the mean \pm standard deviation or median and range for continuous variables and number and percentage for categorical variables. Survival estimates were calculated using the Kaplan-Meier method.

\section{RESULTS \\ Demographic Data}

Of all the operations converting from single ventricular to biventricular physiology, 40 patients who had undergone takedown of BDG, including 3 patients $(7.5 \%)$ who underwent bilateral-BDG takedown during the study period, with a median age of 4.4 years (range, 7 months to 22 years) and median weight of $14.9 \mathrm{~kg}$ (range, 4.7-94.1). Of the $40 \mathrm{pa}-$ tients, 39 underwent SVC-RA reconstruction and 1 was left to drain by way of a large azygous vein. An unbalanced common atrioventricular canal (CAVC) and "borderline hypoplastic left heart" was the most common primary diagnosis, occurring in 15 and 14 patients, respectively (Table 1). A greater proportion of patients had undergone BDG takedown with biventricular conversion in the more recent era (Figure 1). All the patients had undergone $\geq 1$ additional procedure, with the most common being takedown of the Damus-Kaye-Stansel anastomosis (Table 2). Primary SVC-RA anastomosis was achieved in 7 patients $(18 \%)$, and a patch of pericardium, Gore-Tex (W. L. Gore \& Associates) or CorMatrix (CorMatrix Cardiovascular, Inc), was used as an anterior hood in the remaining 33 patients $(82 \%)$. More operative characteristics are listed in Table 3.

\section{Early Outcomes}

One patient died before discharge. The patient had had an unbalanced CAVC and died 5 months after biventricular conversion. An additional patient, with an unbalanced CAVC, who had undergone underwent Fontan takedown, was in the hospital for 37 days before discharge and died 3 days after discharge (cause unknown).

The mean intensive care unit and total hospital length of stay was $28.2 \pm 49.88$ and $38 \pm 59.66$ days, respectively. Of the 40 patients who had undergone BDG takedown, 38 $(98 \%)$ were discharged with biventricular physiology and mild or less biventricular dysfunction.

No evidence was found of any patient having greater than mild stenosis at the SVC-RA anastomotic site using intraoperative direct measurement or intraoperative or discharge echocardiography. No evidence was found of any patient having greater than mild PA stenosis at the previous BDG site using intraoperative assessment of the PA reconstruction, direct intraoperative measurement, intraoperative echocardiography, discharge echocardiography, or on the latest follow-up echocardiogram. After BDG takedown, 34 patients $(85 \%)$ were in normal sinus rhythm immediately postoperatively.

No patients presented with primary SA node dysfunction. Four patients had evidence of postoperative heart block, one of whom required a pacemaker before discharge. Two other patients were discharged with first degree atrioventricular conduction block and one had already had a pacemaker before BDG takedown.

\section{Follow-up}

During a mean follow-up of $3.4 \pm 2.9$ years after BDG takedown (range, 1 month to 9.9 years), 1 additional patient died. Figure 2, $C$, summarizes the Kaplan-Meier survival curve, estimated at $94 \% \pm 4.1 \%$ at 6 months and 1 year and $90.5 \% \pm 5.3 \%$ at 2 years through the latest followup visit. One patient with hypoplastic left heart syndrome, who had undergone biventricular repair developed heart failure and required biventricular assist device placement and subsequent orthotopic heart transplantation 9 months 
TABLE 1. Baseline patient characteristics

\begin{tabular}{lc}
\hline \multicolumn{1}{c}{ Characteristic } & Value \\
\hline Age (y) & \\
Median & 4.4 \\
Range & $0.6-22.7$ \\
BSA (m $\left.{ }^{2}\right)$ & \\
Median & 0.62 \\
Range & $0.28-2.07$ \\
Weight (kg) & \\
Median & 14.9 \\
Range & $4.7-94.1$ \\
Male gender & $19(48)$ \\
Primary diagnosis & \\
Unbalanced CAVC & $15(38)$ \\
Borderline HLHS & $14(35)$ \\
PA-IVS & $4(10)$ \\
TGA-VSD-LVOTO & $3(7.5)$ \\
Severe TR/Ebstein's anomaly & $2(5)$ \\
Left ventricular tumor & $1(2.5)$ \\
Pulmonary stenosis & $1(2.5)$ \\
\hline Data presented as median and range or $\mathrm{n}(\%) . B S A$, Body surface area; $C A V C$, com- \\
mon atrioventricular canal (defect); $H L H S$, hypoplastic left heart syndrome; $P A-I V S$, \\
pulmonary atresia with intact ventricular septum; TGA-VSD- $L V O T O$, transposition of \\
the great arteries with ventricular septal defect and left ventricular outflow tract \\
obstruction; $T R$, tricuspid regurgitation.
\end{tabular}

later. Although it was unlikely to be related to BDG takedown, this patient required balloon dilation of the SVC-RA anastomosis 27 months after transplantation owing to a technical issue in the recipient SVC to donor RA anastomosis.

Two patients developed more than mild SVC stenosis requiring repeat intervention. The mean interval to repeat intervention was $7.7 \pm 4.7$ months. One patient required balloon dilation and surgery and one required balloon dilation, stenting, and surgery. Freedom from SVC-RA reintervention was $94.3 \% \pm 3.9 \%$ at 6 months through the latest follow-up visit (Figure 2, $A$ ).

During the follow-up period, no patients required PA reintervention at the site of PA reconstruction after BDG takedown. One patient, who had previously had an unbalanced CAVC palliated to an extracardiac Fontan, presented after BDG and Fontan takedown with late stenosis of the left PA ostium, remote from the previous BDG site, and required catheter based repeat intervention with balloon dilation and stenting. Freedom from any PA reintervention was $97.1 \% \pm 2.7 \%$ at 6 months through the latest followup visit (Figure 2, B). No patients required surgical reintervention on the PAs.

Eleven patients $(27.5 \%)$ required reintervention ( 1 before discharge) at a mean of $18.7 \pm 25.3$ months (range, 4.1-80.5) after BDG takedown. No reoperations were required to revert to single ventricular physiology. The primary indications for the other reoperations were mitral valvuloplasty, mitral valve replacement, aortic valvuloplasty, subaortic resection, and transplantation. Two of these patients had also required intervention of the SVC as a secondary procedure. Freedom from reintervention was $94.3 \% \pm 3.9 \%$ at 6 months, $77.2 \% \pm 7.6 \%$ at 1 year, and $70.2 \% \pm 8.4 \%$ at 2 to 6 years.

At the latest follow-up visit, no additional patients had presented with new atrial arrhythmias or had required a pacemaker. Because of the limited number of events, we were unable to identify significant predictors of SVC-RA stenosis, PA stenosis, reintervention, or death in patients undergoing BDG takedown.

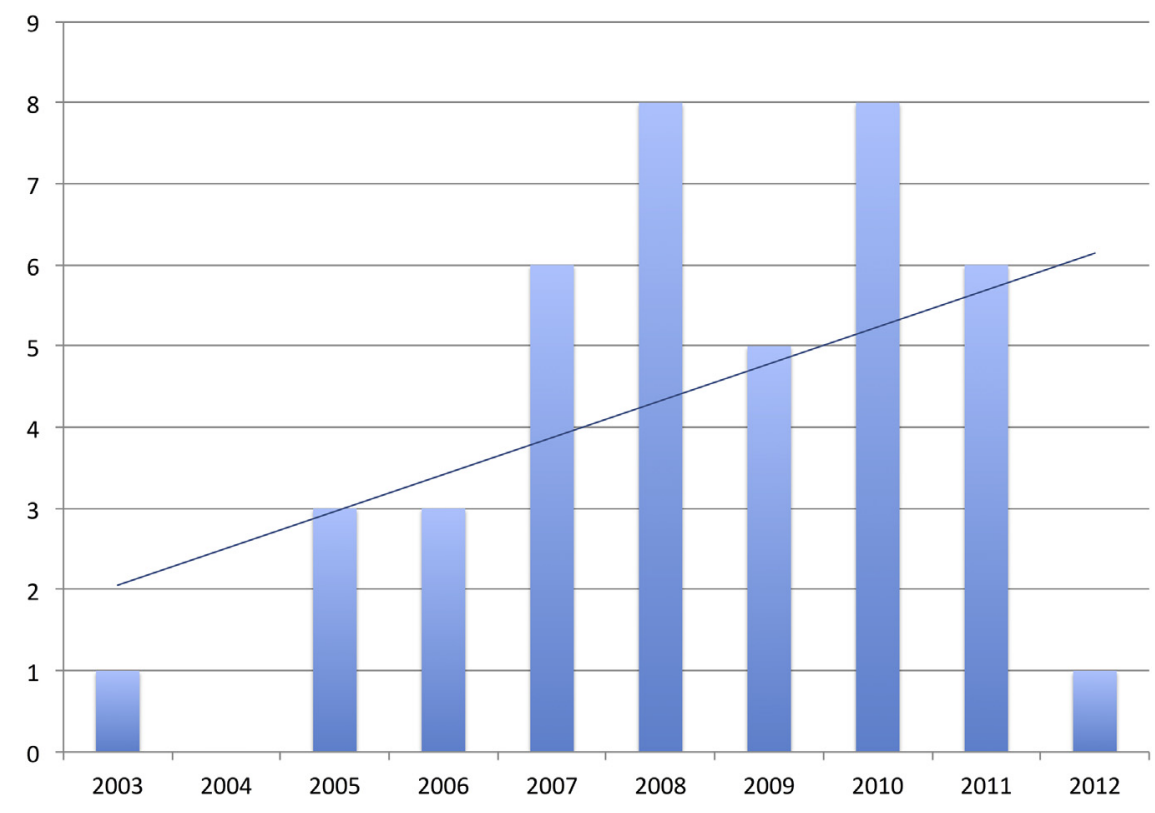

FIGURE 1. Evolution of the number of bidirectional Glenn takedown procedures. 
TABLE 2. Concomitant procedures with takedown of BDG anastomosis

\begin{tabular}{lc}
\hline \multicolumn{1}{c}{ Procedure } & Patients (n) \\
\hline Damus-Kaye-Stansel takedown & 22 \\
Mitral valve repair & 10 \\
ASD repair & 9 \\
Pulmonary arterioplasty & 9 \\
AV canal repair & 9 \\
PVR & 8 \\
BTS takedown & 6 \\
Fontan takedown & 5 \\
VSD repair & 5 \\
Aortic valvuloplasty & 4 \\
Tricuspid valvuloplasty/cone procedure & 4 \\
Ross procedure & 3 \\
Aortic arch augmentation & 3 \\
Subaortic stenosis resection & 3
\end{tabular}

$A S D$, Atrial septal defect; $A V$, atrioventricular; $P V R$, pulmonary valve replacement; $B T S$, Blalock-Taussig shunt; $V S D$, ventricular septal defect.

\section{DISCUSSION}

Historically, BDG takedown was indicated in the setting of complications resulting from SVC syndrome, pulmonary vascular obstructive disease, and the development of collateral circulation between the SVC and inferior vena cava. ${ }^{11-13,15}$ It has been recognized that some patients who initially received single ventricle palliation undergo sufficient ventricular remodeling to achieve biventricular physiology with anatomic correction and thus will no longer require the cavopulmonary anastomosis. However, some have continued to be hesitant to proceed with biventricular repair in young, healthy appearing patients. During the previous decade, improved diagnostic and surgical techniques have allowed us to move toward elective BDG takedown in patients undergoing concomitant procedures on the pathway to biventricular repair. Our institutional approach and the criteria

TABLE 3. Operative characteristics

\begin{tabular}{lc}
\hline \multicolumn{1}{c}{ Characteristic } & Value \\
\hline Patients (n) & 40 \\
Bilateral BDG & $3(7.5)$ \\
Unilateral BDG & $37(92.5)$ \\
Operative time (min) & \\
Crossclamp time & $99 \pm 34$ \\
CPB time & $183 \pm 66$ \\
Patch augmentation & \\
Gore-Tex & $23(58)$ \\
Autologous pericardium & $1(2.5)$ \\
Bovine pericardium & $6(15)$ \\
Pulmonary homograph & $1(2.5)$ \\
CorMatrix & $2(5)$ \\
None & $7(18)$ \\
\hline
\end{tabular}

Data presented as mean \pm standard deviation or $\mathrm{n}(\%) . B D G$, Bidirectional Glenn; $C P B$, cardiopulmonary bypass.
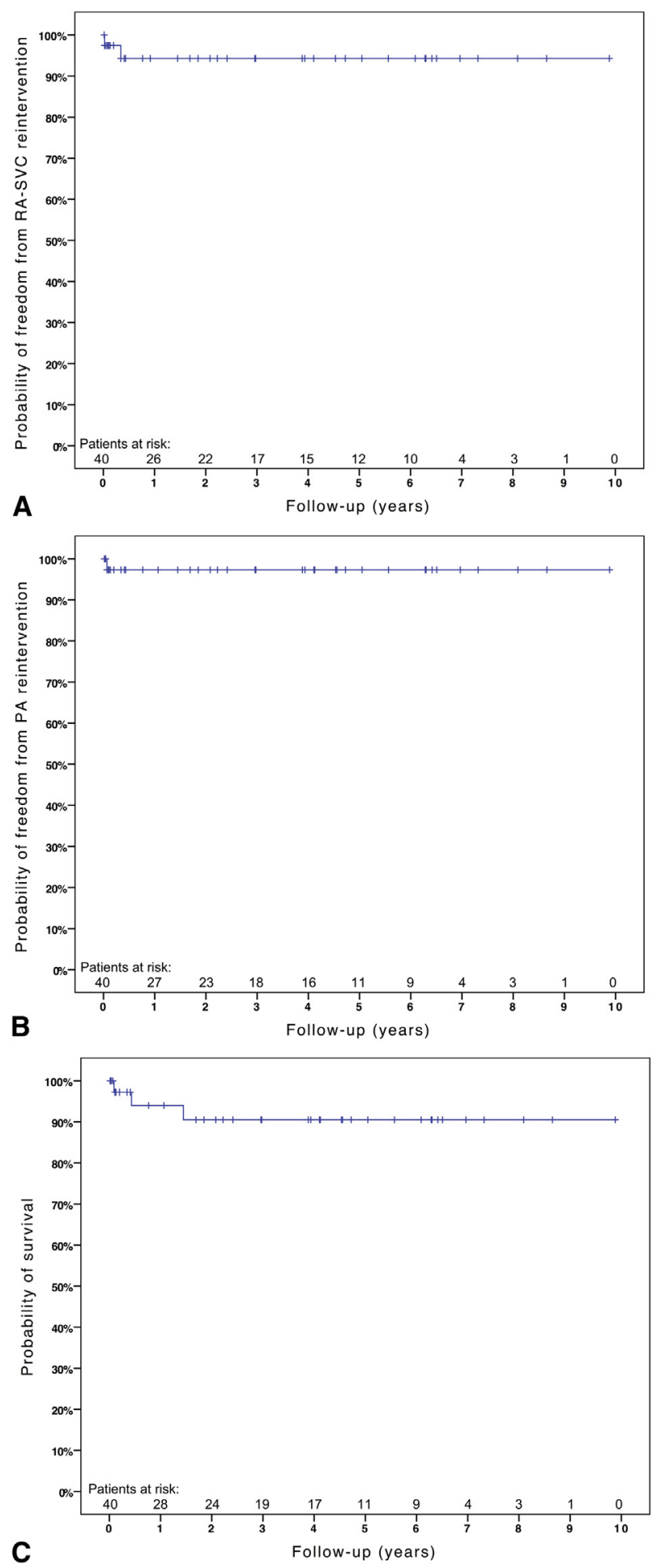

FIGURE 2. Kaplan-Meier estimates of survival and freedom from reintervention. A, Freedom from superior vena cava $(S V C)$-right atrium $(R A)$ reintervention. B, Freedom from pulmonary artery $(P A)$ reintervention. C, Survival.

for biventricular conversion have been previously reported $^{8,9,16-19}$ and were outside the scope of the present report. The success of our results at taking down the 
BDG, defined by no patients requiring reversion back to single ventricular physiology and survival, has been related to the preoperative assessment and decisionmaking using the diagnostic imaging findings.

The sinus node is a subepicardial structure normally located in the RA wall near the SVC entrance on the upper end of the sulcus terminalis. Thus, hesitation has existed about re-establishing SVC-RA continuity for fear of secondary sinus node (SN) dysfunction. ${ }^{20}$ The limited published reports of BDG takedown have often described direct reanastomosis between the SVC and RA; a technique that requires extensive dissection in the vicinity of the SA node and artery. ${ }^{4-6}$ When analyzing the 2-patch repair and the Warden procedure in patients undergoing partial anomalous pulmonary venous return, evidence has supported the notion that significantly more preservation of the SN and its blood supply occurs using Warden's technique, with less SN dysfunction at long-term followup. Data from multiple studies have suggested the incidence of SN dysfunction ranges from $0 \%$ to $6.5 \%$ with a Warden procedure, $\leq 18 \%$ with an incision across the SVC-RA junction, and as great as $55 \%$ with double patch repair. ${ }^{21}$ Thus, to minimize the potential for SN dysfunction in patients undergoing biventricular repair and BDG takedown, techniques to minimize dissection in the vicinity of the SA node and artery have been considered. Recently, a technique that uses a right atrial flap to reestablish SVC-RA continuity was described in a series of patients undergoing conversion to biventricular physiology. ${ }^{14}$ In the present series of patients, we used a similar technique in $82 \%$ of patients, which likely contributed to our low incidence of SN dysfunction.

Biventricular repair, including BDG takedown, is often considered in younger patients. The mean age of patients in our series was 6 years (median, 4.4). In many of the previous reports of older patients, restoration of SVC-RA continuity was achieved with direct anastomosis or synthetic grafts. ${ }^{11-13}$ In younger patients, prosthetic grafts pose a greater threat for thrombosis, necessitating anticoagulation, and have no potential for growth. Furthermore, the SVC is often retracted superiorly and the RA inferiorly, which potentially increases the amount of tension across the anastomosis, predisposing it to the development of stenosis. Therefore, we have generally attempted to reconstruct as much of the SVC-RA anastomosis as possible, using a flap of RA native tissue posteriorly with a patch of nonautologous material anteriorly. Just as this technique has resulted in a low incidence of SN dysfunction by avoiding injury to the SA node and artery, it has also likely contributed to our low incidence of stenosis and reintervention at the SVC-RA junction. In our series, 1 of the 2 patients undergoing subsequent SVC-RA plasty had undergone previous primary reconstruction. The limited number of patients and events precluded us from performing any significant stratification by the type of repair of the SVC-RA junction. However, we have considered using alternatives to Gore-Tex (W. L. Gore \& Associates), owing to the relative thickness and poor pliability of the material, which can impose its shape on the reconstruction, particularly in such a low-pressure system, compared with more pliable materials.

In the era of biventricular conversion, BDG takedown has become a commonly performed concomitant procedure on the pathway to biventricular physiology. The present report has highlighted the results associated with the diagnostic and technical improvements made during the previous decade when considering biventricular repair and BDG takedown. However, it should be cautioned that adequate preoperative decision making regarding the decision to pursue biventricular conversion is crucial, because a biventricular repair that fails can often only be converted to single ventricle palliation with considerably increased risk..$^{22,23}$

\section{References}

1. Glenn WW. Circulatory bypass of the right side of the heart. IV. Shunt between superior vena cava and distal right pulmonary artery: report of clinical application. N Engl J Med. 1958;259:117-20.

2. Kopf GS, Laks H, Stansel HC, Hellenbrand WE, Kleinman CS, Talner NS. Thir ty-year follow-up of superior vena cava-pulmonary artery (Glenn) shunts J Thorac Cardiovasc Surg. 1990;100:662-70; discussion 670-1.

3. del Nido PJ, Baird C. Congenital mitral valve stenosis: anatomic variants and surgical reconstruction. Semin Thorac Cardiovasc Surg Pediatr Card Surg Annu. 2012;15:69-74.

4. Baird CW, Myers PO, Del Nido PJ. Aortic valve reconstruction in the young infants and children. Semin Thorac Cardiovasc Surg Pediatr Card Surg Annu. 2012;15:9-19.

5. Baird CW, Myers PO, Marx G, Del Nido PJ. Mitral valve operations at a highvolume pediatric heart center: evolving techniques and improved survival with mitral valve repair versus replacement. Ann Pediatr Cardiol. 2012;5:13-20.

6. Myers PO, Bautista-Hernandez V, del Nido PJ, Marx GR, Mayer JE, Pigula FA, et al. Surgical repair of truncal valve regurgitation. Eur J Cardiothorac Surg. 2013;44:813-20.

7. Myers PO, Tissot C, Christenson JT, Cikirikcioglu M, Aggoun Y, Kalangos A. Aortic valve repair by cusp extension for rheumatic aortic insufficiency in children: long-term results and impact of extension material. J Thorac Cardiovasc Surg. 2010;140:836-44.

8. Emani SM, Bacha EA, McElhinney DB, Marx GR, Tworetzky W, Pigula FA, et al. Primary left ventricular rehabilitation is effective in maintaining twoventricle physiology in the borderline left heart. J Thorac Cardiovasc Surg. 2009; 138:1276-82.

9. Emani SM, McElhinney DB, Tworetzky W, Myers PO, Schroeder B, Zurakowski D, et al. Staged left ventricular recruitment after single-ventricle palliation in patients with borderline left heart hypoplasia. J Am Coll Cardiol. 2012;60:1966-74

10. Malhotra SP, Petrossian E, Reddy VM, Qui M, Maeda K, Suleman S, et al. Selective right ventricular unloading and novel technical concepts in Ebstein's anomaly. Ann Thorac Surg. 2009;88:1975-81; discussion 1981.

11. Marcelletti C, Wallace RB, Ritter DG. Reconstruction of superior vena cava-right atrial continuity and "anatomic" repair of transposition of great arteries with ventricular septal defect. Mayo Clin Proc. 1976;51:163-6.

12. Pacifico AD, Kirklin JW. Take-down of cava-pulmonary artery anastomosis (Glenn) during repair of congenital cardiac malformations: report of 5 cases. J Thorac Cardiovasc Surg. 1975;70:272-7.

13. Rohmer J, Quaegebeur JM, Brom A. Takedown and reconstruction of cavopulmonary anastomosis. Ann Thorac Surg. 1977;23:129-34.

14. Baird CW, Forbess JM. Takedown of cavopulmonary (Glenn) shunt: a technique using a right atrial flap. J Thorac Cardiovasc Surg. 2012;143:747-9.

15. Bruckheimer E, Bulbul ZR, Hellenbrand WE, Kleinman CS, Kopf GS. Takedown of Glenn shunts in adults with congenital heart disease with 
polytetrafluoroethylene grafts: technique and long-term follow-up. $J$ Thorac Cardiovasc Surg. 1997;113:607-8.

16. Emani SM, del Nido PJ. Strategies to maintain biventricular circulation in patients with high-risk anatomy. Semin Thorac Cardiovasc Surg Pediatr Card Surg Аппи. 2013;16:37-42.

17. Kalish BT, Banka P, Lafranchi T, Tworetzky W, Del Nido P, Emani SM. Biventricular conversion after single ventricle palliation in patients with small left heart structures: short-term outcomes. Ann Thorac Surg. 2013;96:1406-12.

18. Nathan M, Liu H, Pigula FA, Fynn-Thompson F, Emani S, Baird CA, et al. Biventricular conversion after single-ventricle palliation in unbalanced atrioventricular canal defects. Ann Thorac Surg. 2013;95:2086-95; discussion 2095-6.

19. Baird CW, Myers PO, Marx G, Nathan M, Kalish BT, Tworetzky W, et al. Biventricular repair in patients with a borderline left heart. In: Da Cruz EM, Ivy D,
Jaggers J, eds. Pediatric and Congenital Cardiology, Cardiac Surgery and Intensive Care. London: Springer; 2014:1765-85.

20. Ferrer MI. The sick sinus syndrome in atrial disease. JAMA. 1968;206 645-6.

21. Okonta KE, Agarwal V. Does Warden's procedure reduce sinus node dysfunction after surgery for partial anomalous pulmonary venous connection? Interact Cardiovasc Thorac Surg. 2012;14:839-42.

22. Davis CK, Pastuszko P, Lamberti J, Moore J, Hanley F, El Said H. The hybrid procedure for the borderline left ventricle. Cardiol Young. 2011;21:26-30.

23. Hickey EJ, Caldarone CA, Blackstone EH, Lofland GK, Yeh T Jr, Pizzaro C, et al Critical left ventricular outflow tract obstruction: the disproportionate impact of biventricular repair in borderline cases. J Thorac Cardiovasc Surg. 2007;134 1429-36; discussion 1436-7. 